\title{
Energy Efficient Control of Three-Phase Induction Motor - A Review
}

\author{
C. Thanga Raj, Member IACSIT, S. P. Srivastava, and Pramod Agarwal
}

\begin{abstract}
Due to robustness, reliability, low price and maintenance free, induction motors (IMs) used in most of the industrial applications. The influence of these motors (in terms of energy consumption) in energy intensive industries is significant in total input cost. This paper presents a review of the developments in the field of efficiency optimization of three-phase induction motor through optimal control and design techniques. Optimal control covers both the broad approaches namely, loss model control (LMC) and search control (SC). Optimal design covers the design modifications of materials and construction in order to optimize efficiency of the motor. The use of Artificial Intelligence (AI) techniques such as artificial neural network (ANN), fuzzy logic, expert systems and nature inspired algorithms (NIA), Genetic algorithm and differential evolution in optimization are also included in this paper. Experimental and simulation examples on efficiency optimization are illustrated.
\end{abstract}

Index Terms - design optimization, induction motor, optimal control, SPEED software.

\section{INTRODUCTION}

Induction motor is a high efficiency electrical machine when working closed to its rated torque and speed. However, at light loads, no balance in between copper and iron losses, results considerable reduction in the efficiency. The part load efficiency and power factor can be improved by making the motor excitation adjustment in accordance with load and speed. To implement the above goal, the induction motor should either be fed through an inverter or redesigned with optimization algorithms.

The optimization of induction motor design with AI and NIA has received considerable attention recently. The design optimization of a three-phase induction motor can be formulated as a general non-linear programming and the standard non-linear programming (NLP) techniques can be used to solve it. But this techniques are computationally very expensive and inefficiency whereas NIA is competent tool to solve NLP. Extensive work has also been done on inverter-fed induction motor design in order to realize torque ripples and harmonic currents. Some of the design optimization results are available in [1]-[23].

Manuscript received September 17, 2008.

C. Thanga Raj is with Department of Electrical Engineering, Indian Institute of Technology Roorkee, India (e-mail: ctrajdee@iitr.ernet.in ).

S.P. Srivastava is with Department of Electrical Engineering, Indian Institute of Technology Roorkee, India (e-mail: satyafee@ iitr.ernet.in).

P. Agarwal is with Department of Electrical Engineering, Indian Institute of Technology Roorkee, India (e-mail: pramgfee@iitr.ernet.in).
In optimal control, there are two main approaches to improve the induction motor efficiency at light loads, namely loss model controller (LMC) [24]-[65], search controller (SC) [66]-[80] for minimum power input. References [81] - [83] described both LMC and SC, [84] - [89] described other controls of IM efficiency optimization and [90] - [95] described soft starting to improve motor performance. LMC determines the optimal air gap flux through the motor loss model. In case of SC, it measures the input power of the drive and searches for optimum flux or excitation current.

This paper describes the various types of optimization techniques including soft computing to induction motor efficiency optimization in section II, Optimum design of induction motor is given in section III, the review of loss model controller and search controller applied to IM efficiency optimization are given in section IV and V respectively and this paper concludes in section VI.

\section{OPtimization TeChNiQues}

Optimum design of induction motor is a non-linear multi dimension problem whereas optimal control is a single or two dimension problems. Therefore the role of optimization techniques is more important in design than control of IM to get global optimum.

\section{A. Conventional Optimization Techniques}

Statistical method [1], Monto Corlo [2], Sequential Unconstraint Minimization Technique (SUMT) [11], [12], modified Hook Jeeves [3], Han Powel method [4], modified Han Powel method [5] are the few methods which applied successfully in IM design in the past.

\section{B. AI Based Optimization Techniques}

There are many types of AI controllers applied to IM optimization through control as well as design and are available in the literature [35], [36], [63], [77] - [80]. Some controllers use Fuzzy [653], [77]-[80], ANN [35], [36]. Fast convergence can be achieved by these controllers.

\section{NIA Based Optimization Techniques}

Nature Inspired Algorithms (NIA) are relatively a newer addition to class of population based stochastic search techniques based on the self organising collective processes in nature and human artefacts. Some popular NIA are Genetic Algorithms (GA) [61], [62], [18], Particle Swarm Optimization (PSO) [48]-[51], [23], Evolutionary Algorithm [98], Simulated Annealing (SA) [19], [22], and Evolution Strategy [21], etc. NIA seem promising because of their social - cooperative approach and because of their ability to 
adapt themselves in the continuously changing environment. .

\section{DESIGN OPTIMIZATION OF INDUCTION MOTOR}

\section{A. Conventional Algorithms}

In Ref [6], Hook Jeeves search method used to find optimal design sheet of IM. Efficiency, efficiency-cost and cost are considered as objective functions. Authors analyzed the effects of supply voltage variation in the motor performance and concluded that higher efficiency can be obtained by increasing the voltage. Service condition has been considered in [7] before taking the design optimization of IM. From the author's conclusion of above paper, the pump load systems, the following modifications are helped to consume minimum energy, (i) stator core length increase up to $130 \%$, (ii) number of stator winding turns decrease up to $10 \%$.

Hydraulic pump in aerospace applications have been considered in [8] for design optimization. Supply frequency, environment, inrush current are considered as constraints in addition with normal constraints. Two level optimization carried out in [9], one was material cost and other was operating cost. A global optimization approach has been introduced in [10]. Here error is taken as objective function (for efficiency maximization, calculate efficiency in each step and find error (100-efficiency)). If error is more, large step size was used for adjusting variables.

Sequential unconstraint minimization technique (SUMT) was successfully applied to optimize IM in [11], [12]. Torque pulsation has been considered in [11] as an additional constraint for a inverter fed IM design. Authors suggested that the flux and higher order harmonic currents are as low as possible to have least pulsation. Reactance should be maintained at least 4 times greater than normal machine. Stack length and stator and rotor current densities to be decreased. Also to have a least pulsation, select stator core depth greater, rotor slot depth deeper and larger stator bore dia.

In Ref [13], constraint Rosenbrock method (Hill Algorithm) used to optimize the motor. Material cost has considered as an objective function and concluded that higher value of current densities required for getting optimum value. Six to four pole machines are to be selected for adjustable speed applications even $3600 \mathrm{rpm}$ speed required, suggested in [14].

Sequential quadratic programming (SQP) for non-linear constraint optimization technique was successfully implemented to IM design in [15]. In this paper, authors have included practical considerations to reduce the computation time. The following are the practical considerations [15],

\section{- Effects of different starting vectors:}

Here the starting values of variables are taking their lower limit, upper limit and intermediate values. Then the analysis was carried out in the objective function value iteration by iteration. The values of the variables available in the literature have also considered for analysis. Out of four combination of variables, the upper limit value of variation offered poor results at starting but good results at final iteration.

- Effect of different step size:

Authors have observed that the step size for increasing variable values is too small (less than $10^{-3}$ ) or too big (greater than 0.1) deteriorates the result in $30 \mathrm{~kW} \mathrm{IM} \mathrm{and}$ recommended to set the value 0.005 as step size to get good results.

- Effect of constraints:

There was no distinct difference between different sets of constraints considered, said the authors.

- Effect of changing objective function:

Authors considered various types of objection function like efficiency, power factor, torque and observed that efficiency slightly affected when torque was considered as an objective function.

- Change of variables and performance parameters with iteration:

Authors set the entire variables to upper limits and analyzed the performance related parameters with iteration. From the observation, efficiency and power factor were almost same from second iteration onwards.

Stator copper losses and core losses including harmonic losses are reduced by optimal selection of stator slot design in [16]. Authors used finite element method (FEM) to design the same and reduced core and winding losses by $2.22 \%$. IM efficiency has been improved in [17] by modifying production technological process and is called as no tooling cost (NTC). It does not require a complete redesign of laminations. Authors modified the following in a totally enclosed fan cooled standard IM, (i) the rotor with copper bar included in the slot before the aluminium die cast of the cage, (ii) increase of the core axial length, (iii) Annealing of the stator core. Authors finally concluded that the production cost for higher efficiency motors in considerably reduced by NTC.

\section{B. AI and NIA Based Algorithms}

GA is applied to IM design and achieved $25 \%$ reduction of the total cost. Most of the NIA have considered in [18] for IM efficiency maximization. Hybridization of evolutionary programming (EP) and simulated annealing (SA) also proposed and applied to IM design [19]. Here EP is used to searching optimum point where as SA assists EP to converge towards the optimum point. Authors concluded that EPSA (hybrid) was performed well, where as DE performed well if hybridization not applied.

Evolutionary algorithm (EA) was applied in [20] and got good results in terms of convergence time/ global convergence and the ability to handle discrete variables. Improved evolution strategy (ES) (hybrid of SA and GA) has been considered in [21] for the motor design serving to electric vehicle. Shaking technique was included to avoid 
local minima which appear in conventional ES. In Ref [22], authors used SA to design $3 \varphi$ induction motor and concluded that SA performed better than conventional methods. Improved PSO with quadratic interpolation has been used in [23].

\section{Optimal CONTROL OF InduCTION MOtOR THROUGH LOSS MODEL}

Optimum control of IM is essential one because it is not possible to optimize the motor efficiency for every operating point by optimizing machine design. In many applications of constant speed operation, induction motor operate under partial load for prolong periods, such as spinning drive in textile industry [24], mine hoist load, drill presses and wood saw. In these applications, induction motor should operate at reduced flux causes a balance in between iron losses and copper losses results efficiency improvement. A simplest method to improve efficiency of induction motor operates at light load is to keep the motor connection in star results reduced power consumption. When the motor run in star mode, the voltage applied to stator phase winding is reduced by the factor $\sqrt{3}$. Since the torque developed in the motor is directly proportional to square of the voltage, the developed torque in star mode is also reduced by the factor 3 . Therefore, the motor can be operated in star mode up to 0.33 p.u loads.

In this case the developed torque of the motor should be measured and find sufficient to drive the control system and also measure the temperature to be normal. Even though this method is not suitable for wide range of partial loads still it is working with many textile industries in India. Here no switching losses due to the absence of power electronic controllers.

The role of loss model controller is to measure the speed and stator current and determines optimal air gap flux through the loss model of the motor. The inner part of the control algorithm may be in scalar [25] - [45] or vector [46] [65]. In scalar control technique, variables are controlled in magnitude only whereas in vector control, variables are controlled in magnitude and phase. The complex induction motor can be modeled as DC motor by performing simple transformation in the vector control scheme

One advantage of loss model controller is that no delay in calculation of optimal flux and drive performances but time delay occurs in case of search control due to the search.

Artificial intelligence controllers like ANN, fuzzy, PSO, GA can also be used for finding optimal flux level with minimum time. The exact values of machine parameters including their variations due to core losses and main inductance flux saturation are required in this approach. Fig. 1 [24] shows the different part of losses in the induction motor. Many researchers have been reported several strategies using different variables to minimize losses in IM. Some algorithms use slip speed [24], [29], [30], rotor flux [54], [55], excitation current [52], voltage [31]. The general block diagram of energy optimal control using PSO and fuzzy logic is shown in Fig. 2. Here fuzzy logic is used to maintain good stability of the drive during flux change at optimal control.

\section{A. Scalar Controlled Drives}

The behavior of an ac induction motor drive is described by three independent variables- the speed, the terminal voltage, the terminal frequency- and the parameters of the motor and its power supply [25]. At any operating point characterized by the speed and torque, an optimal flux (in other words, ratio of voltage and frequency) can be found that meets the requirement of the operating point and minimizes the overall losses. Losses of the IM are represented by resistances in the equivalent circuit shown in Fig. 3 [26]. The stray load losses are represented by the equivalent resistance $\mathrm{r}_{\text {str }}$ in the stator side. As in Fig. 3, the power losses in the resistances depends on stator current and should be measured it to calculate optimal air gap flux as well as to avoid over current flow in the motor [27].

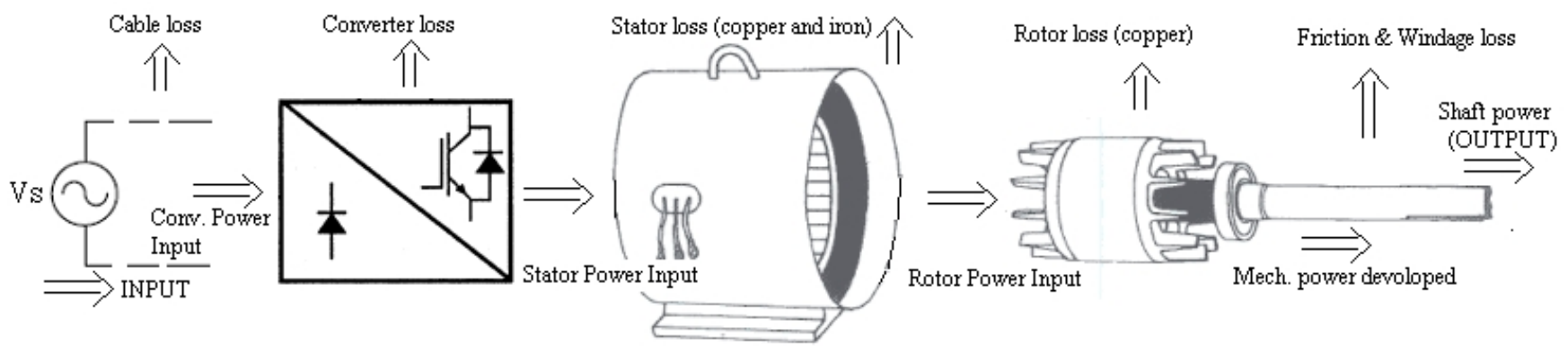

Fig. 1 Losses in the induction motor drive system 


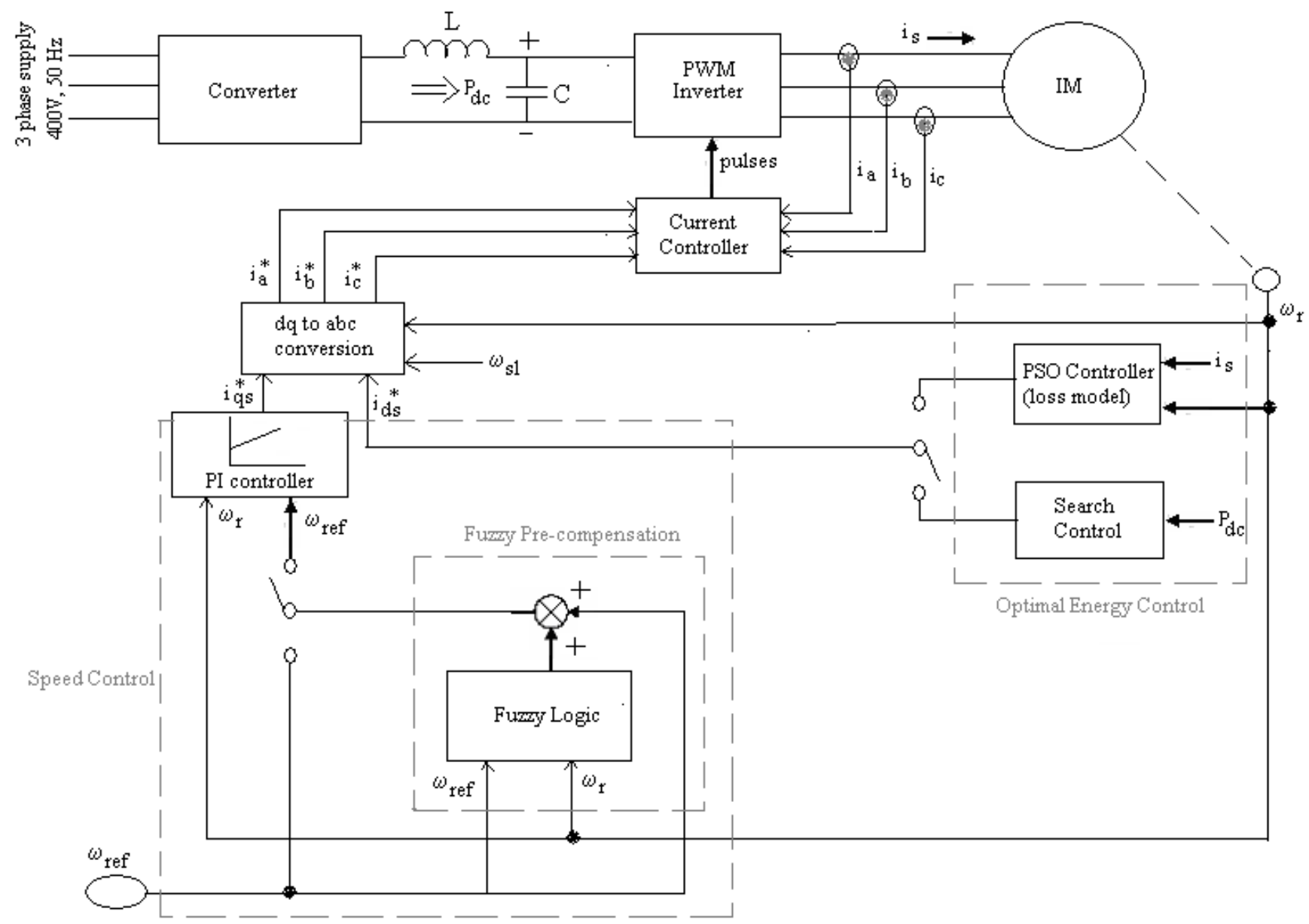

Fig. 2. Block diagram of optimal energy and speed control using PSO and fuzzy logic

\section{(i) Conventional Controllers}

In Ref. [27], a loss model controller with detailed analysis for minimizing the losses in scalar controlled induction motor is presented and suggested that the air gap flux is always kept greater than 0.3 pu independently on LMC command. This is because of very low flux creates more motor currents and disturb torque and finally losses will be more. Authors of the above paper concluded that rated flux operation essential during transient (starting) to maintain good dynamics. The detailed study on efficiency optimization of scalar controlled IM is available in [28].

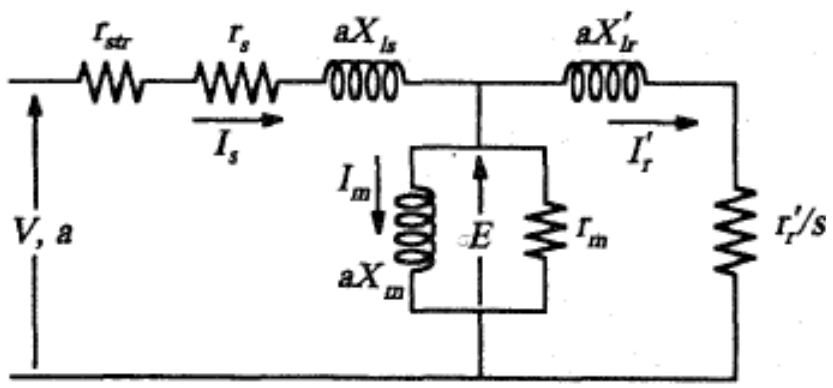

Fig.3 Per unit induction motor equivalent circuit

The procedure described in [29] is based on optimal slip control of current source inverter fed induction motor. First, the optimal slip is searched by trial and error with the help of loss model and the results are tabulated microprocessor memory. Then the motor is operated at optimal efficiency by simply tracking the optimal slip given in the table. The span of the optimal slip with respect to torque is high in case of lower speed rated motors and is shown in Fig. 4 [29]. Optimization was carried out successfully at centrifugal pump drives and is available in [30].

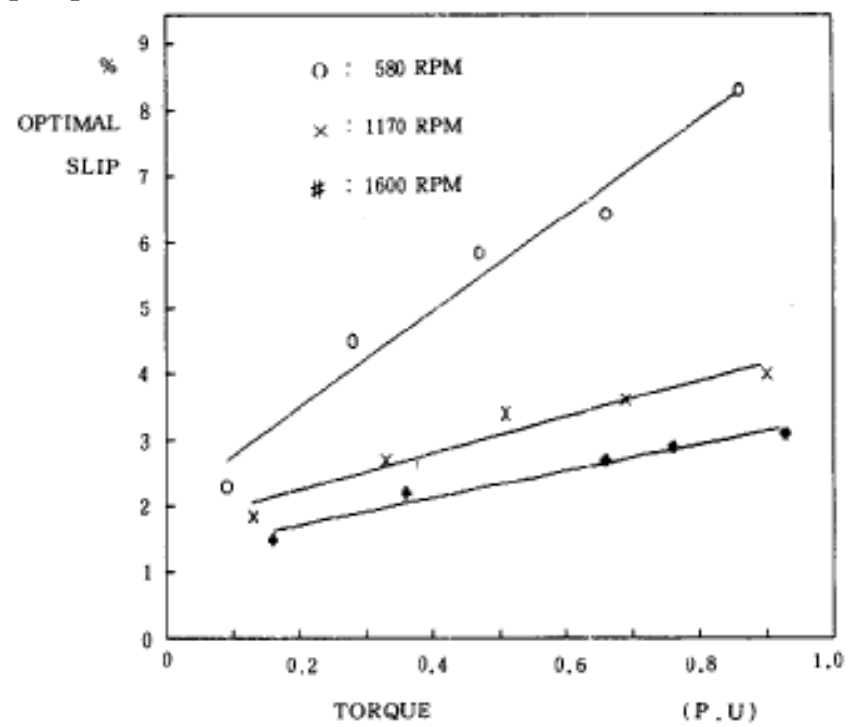

Fig. 4 Optimal slip versus torque at various speed

The variables, input voltage and frequency are considered to optimize the motor efficiency in [31]. Authors achieved $10-15 \%$ of efficiency improvement in a $2 \mathrm{hp}$ induction motor at $0.4 \mathrm{pu}$ load. Core saturation, source harmonics and skin effects are included in their research.

It should be noted that the flux level can be adjusted to get 
maximum efficiency without considering inverter losses in small drives less than $10 \mathrm{~kW}$; but the effect of inverter losses in medium size $(10-1000 \mathrm{~kW})$ drives is significant [32]. Authors concluded from the experiments that no critical issues in the drive operation when the converter losses are neglected but the robustness will decrease when disturbance occurs. As an example, Fig. 5 [32] shows the converter, drive and motor losses versus load torque in $90 \mathrm{~kW}$ drive and demonstrates that a reduction in converter losses by flux reduction at very low speed. More studies on efficiency optimization of scalar controlled IM was carried out in [33]-[43].
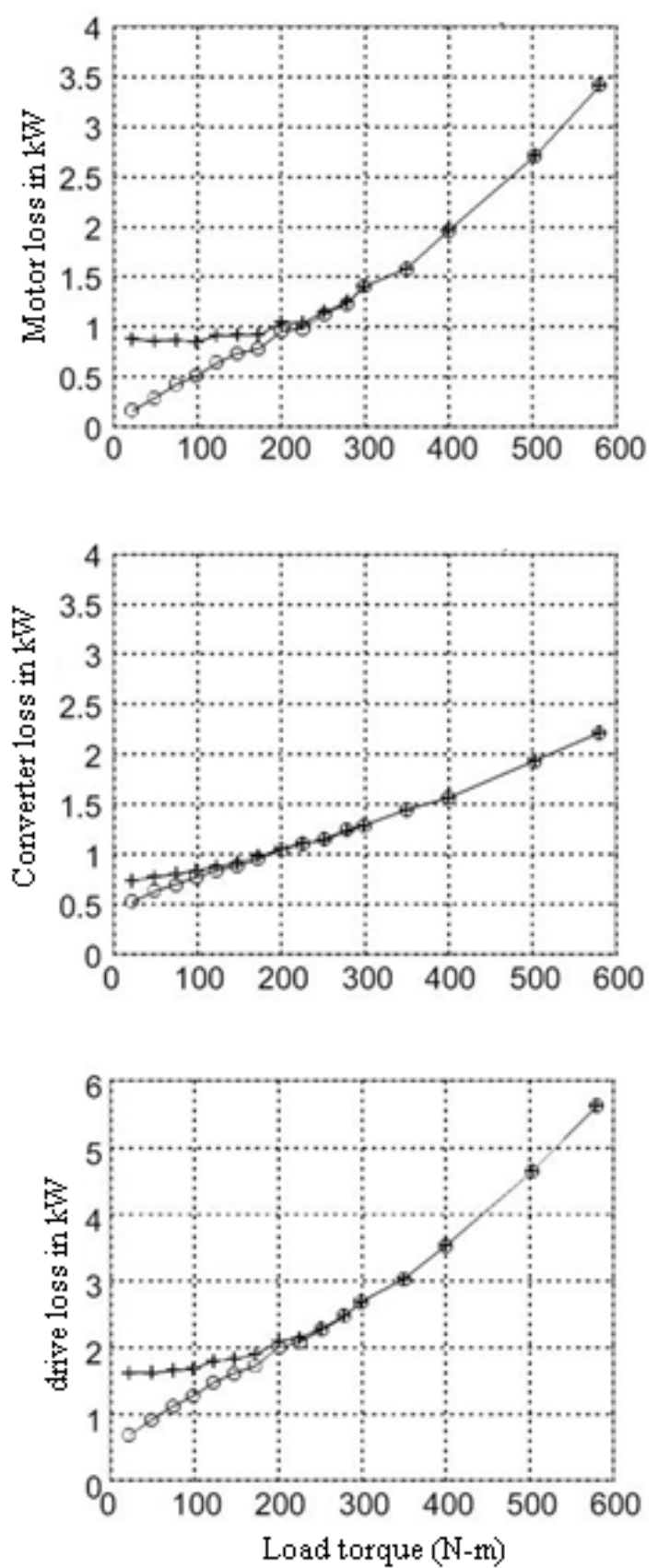

Fig. 5 Converter, drive and motor losses in $90 \mathrm{~kW}$ motor at $900 \mathrm{rpm}$ speed.

\section{(ii) AI and NIA Base Controllers}

Many recent developments in science, economics and engineering, demand numerical techniques for searching global optima to corresponding optimization problems [44]. As we discussed earlier, the effect of motor parameter variations has been focused in [45] and GA is used to search motor parameter to avoid error in the loss model. Then optimum voltage and frequency arranged as table for the energy saving controller. A 3-3-1 feed forward neural network $(\mathrm{NN})$ has been used in [46] to implement loss model controller. The inputs to the NN are torque, speed and rotor resistance of the IM and the output is the optimum rotor flux to minimize total losses. In Ref. [47], authors used offline NN to find optimal voltage values to the best efficiency of the IM in a short time and also only two step changes in the voltages required irrespective of load to settle in the desired speed or torque.

In Ref. [48]-[50], authors used particle swarm optimization (PSO) as a searching tool to find the optimal value of variables for which the objective is maximum/minimum. Slip speed is considered in [48], [49] and the values of flux and hysteresis bands are considered in a direct torque controlled IM [50] as a variable to minimize losses. ANN used for implementing optimum variables in the controllers.

PSO is used to adjust proportional -integral- differential controller gains in [39] and get less torque and speed ripples in the drive. In Ref. [24], authors used differential evolution to find optimal slip speed from the loss model of the induction motor. A real load (textile spinning drive) diagram has been considered in that paper and authors shown that US $\$ 563136$ per year can be saved at a medium size textile industry in Tamil Nadu, India.

\section{B. Vector Controlled Drives}

In vector control, the variables are considered in magnitude and phase. This technique of control needs more calculation than scalar control. The field oriented controller (FOC) generates the required reference currents based on the reference torque.

\section{(i) Conventional Controllers}

Generalized $\mathrm{d}-\mathrm{q}$ loss (vector) model including core saturation effects is presented in [52] and optimized IM, permanent magnet synchronous motor, direct current motor, synchronous reluctance motor through optimal excitation current (ids). Authors took optimal ids calculation less than $7 \mu \mathrm{s}$ in an experimental set up and concluded that minimum losses are reached when $\mathrm{d}$ axis power losses equal to $\mathrm{q}$ axis power losses. Fig. 6 [53] shows the induction motor equivalent circuits in $\mathrm{d}-\mathrm{q}$ coordinates with stator and rotor core loss resistances.
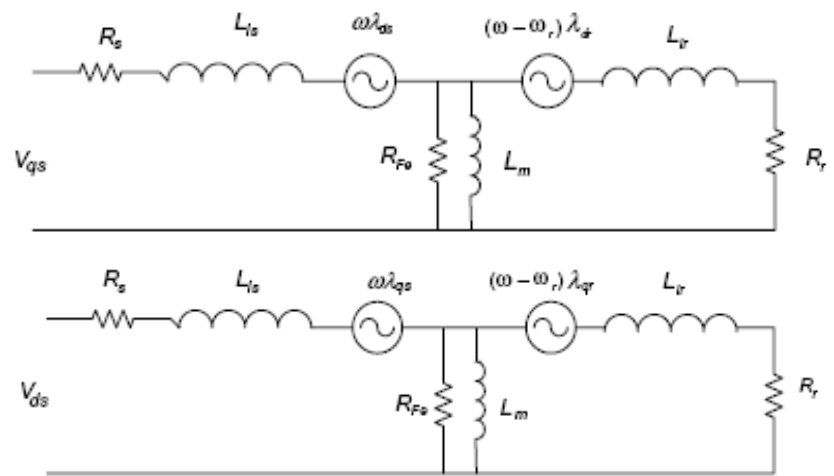
Fig. 6 loss model of IM with d-q co-ordinates

Parameter variations effects during losses minimization in induction motor through the simple IM loss motor including iron losses are studied in [54] and achieved minimum electromagnetic losses by proper adjustment of magnetic flux The procedures to get minimum energy in [55] are that derive the study state values of currents and fluxes for the given load first and design the steady state feedback control based on lyapunov. Then implemented the steady state values in real time and finally got good torque stability when minimum energy operation of IM.

In Ref [56], loss minimization algorithm (LMA) has been simplified with a voltage dependant source and loss resistance. Authors considered current and voltage constraints when searching the optimal flux level and suggested that the model without leakage reactance yield a higher loss than the actual one.

The modified equivalent circuit of IM in d-q coordinates is presented in [57] (shown in Fig. 7) with the consideration of inverter switching losses. The newly defined parameters $\mathrm{R}_{\mathrm{ls}}$, $\mathrm{R}_{\mathrm{lr}}$ are stator and rotor resistances respectively. Stray load losses associated with stator and rotor leakage fluxes. Authors of Ref [57] determined harmonic iron losses in laminated iron cores under non-sinusoidal excitation. Minimum time- minimum loss speed control of IM described in [58].
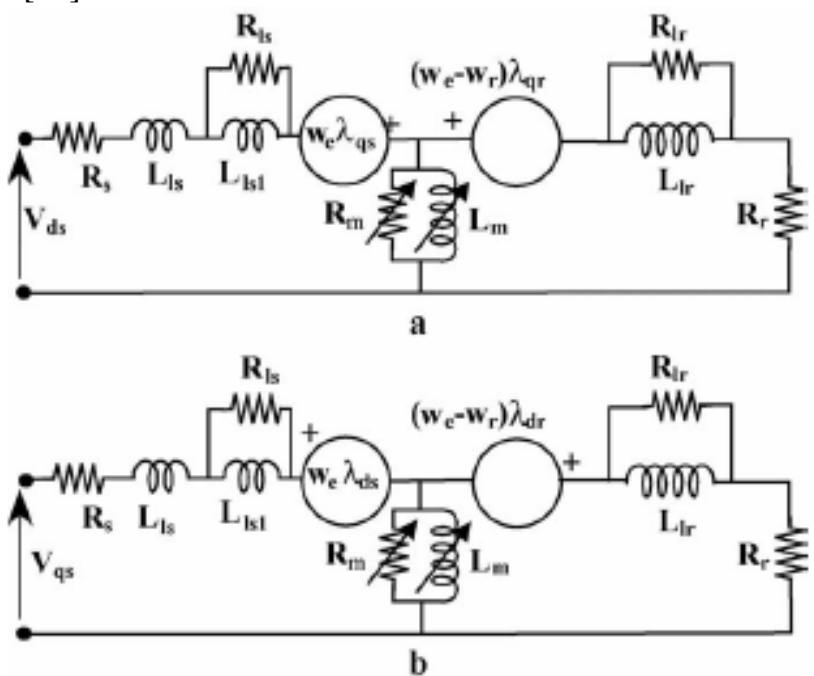

Fig. 7 Modified equivalent circuits for induction motor dynamic model. (a) $\mathrm{d}$-axis equivalent circuit (b) $\mathrm{q}$-axis equivalent circuit

Two common problems on lightly loaded motor are highlighted in [59], that are (i) large speed drop when increasing sudden load torque, (ii) slow acceleration. Authors proposed one algorithm which distributed stator current optimally into the flux producing current and torque producing current during a sudden load torque impact occurring at light load. The algorithm accounted main flux saturation effects in the machine and shows the dynamics of the flux variation. Fig. 8 [59] shows the effectiveness of optimal dynamic current sharing technique in $2.2 \mathrm{~kW}$ IM drive (fixed load torque, $50 \mathrm{NM}$ ).

\section{(ii) AI Based Controllers}

A hybrid technique, GA-PSO based vector control of induction motor for loss minimization as well as torque control is presented in [60]. PSO as used for mutation process of GA so that the learning efficiency of GA was improved. Floating point GA is applied in [61] for minimizing IM losses through flux adjustment. Basic GA is used in [62] to identify rotor time constant from the error between motor and commanded stator currents, which helped on-line adjustment of slip angular speed. Optimum flux producing current and corresponding efficiency are focused in [63], [64] by using neural network. Change in core loss resistance due to flux and frequency have taken into account. The variation in the iron loss resistance can be found from the equation (1) [63], where $R_{m b}$ is the value of $R_{m}$ at rated frequency and flux.

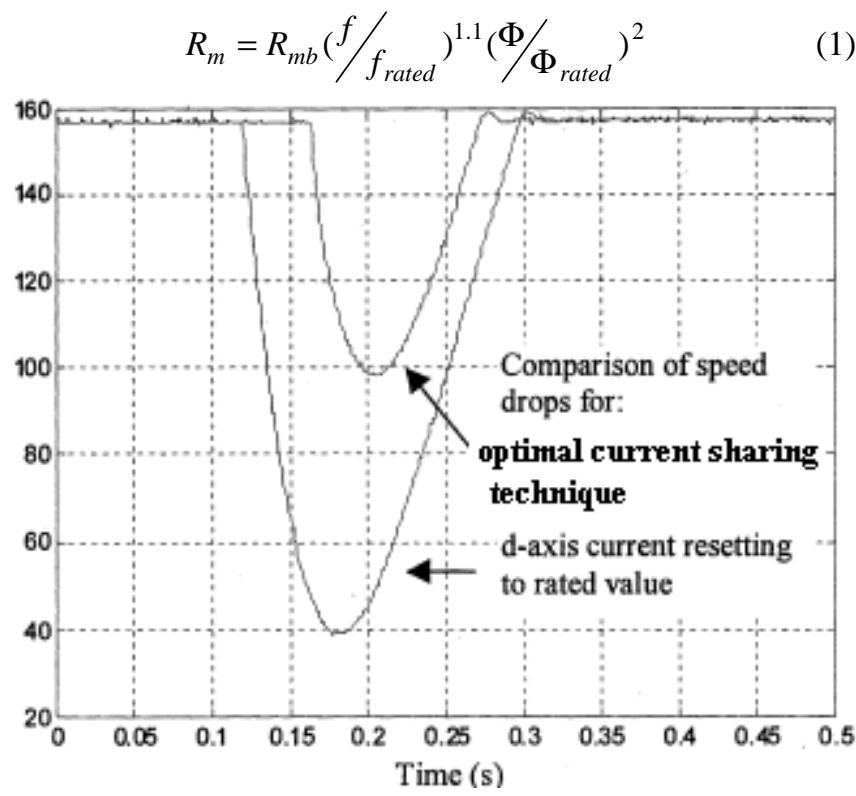

Fig. 8 Speed drops for the 2.2-kW induction motor drive (load torque stepped to $50 \mathrm{Nm}$ )

\section{OPtimal CONTROL OF INDUCTION MOTOR THROUGH SEARCH CONTROL}

Search control (SC) does not require the knowledge of the motor loss model for implementing optimization controllers. This controller measures the input power of the machine drive regularly at fixed interval and searches optimal flux value which results in minimum power input or stator current for the given values of speed and torque. Torque ripple always presents in SC due to the oscillations in the air gap flux.

IM efficiency optimization through search control was successfully carried out in [65]-[79]. The advantages of SC control in induction motor efficiency optimization are as follows [71],

- If the power input is measured on the source side of the rectifier, the minimization is not restricted to the motors but affects the entire system and thus reduces the total amount of energy consumed.

- Since the source voltage and current waveforms have a much smaller harmonic content than the corresponding motor waveforms, the power measurement is more accurate and easier to obtain. 
- Insensitive to parameter variation in the motor due to thermal and core saturation effects.

\section{(i) Scalar Controlled Drives}

In Ref [72], authors described the problems arised when the input power is considered instead of stator current as the controlled variable to optimize the efficiency of IM. When stator current used as variable, its minimum can be more easily detected than the input power. Stator current leads more loss reduction and less torque ripple due to the absence of oscillation in the air gap flux. Fig. 9 [73] shows the loss minimization process in the $1 \mathrm{hp}$ drive when both the controlled variables are considered and it revealed that power input to the drive is smaller in stator current minimization than the power input minimization.

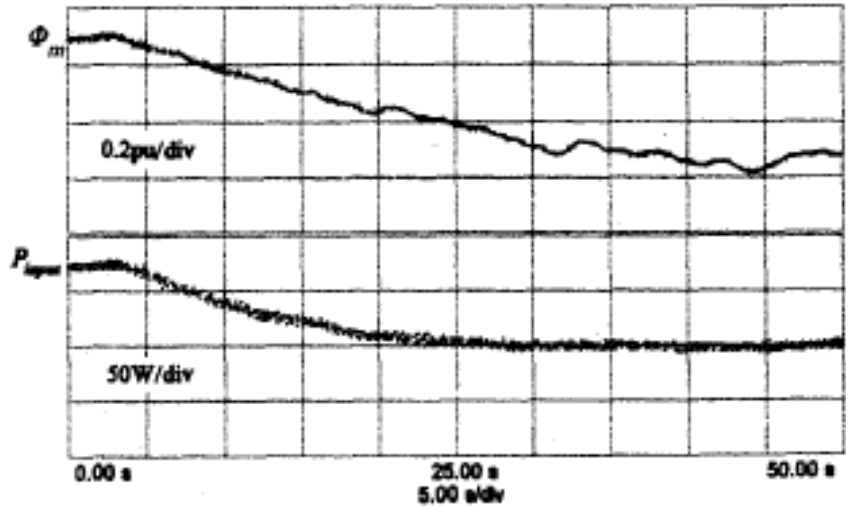

(a)

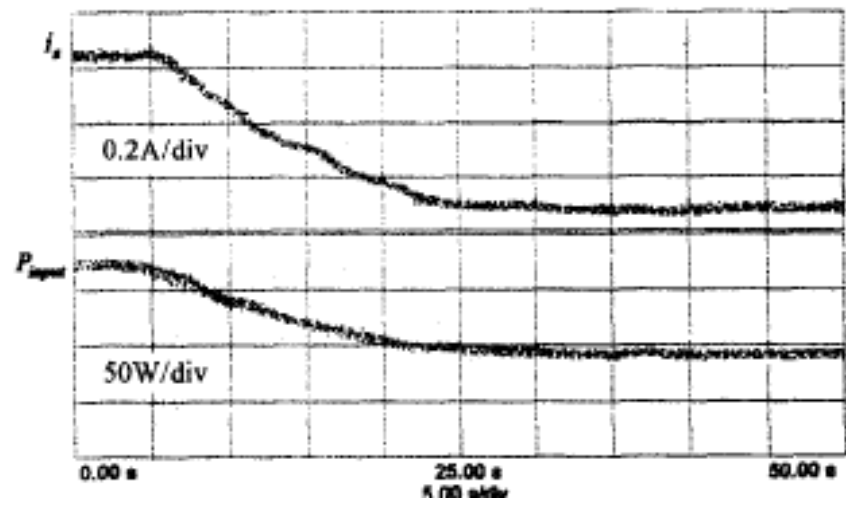

(b)

Fig. 9 Loss minimization on process in the 1-hp drive when the controlled variable IS (a) the input power and (b) the stator current

Minimum power input to the drive is achieved by adjusting inverter input frequency in [73]. Authors have shown a significant efficiency improvement than $\mathrm{v} / \mathrm{f}$ control and concluded that large energy saving potentials available in pump and fan drives. In Ref [74], voltage adjustment was carried out according to losses for minimum power input and the second controller changed the frequency to correct rotor speed losses caused by voltage drops. The third controller produced an initial commanded frequency which compensates the variation in slip with changing load and speed. Fig. 10 [74] shows the voltage perturbation optimization control.

\section{(ii) Vector controlled Drives}

Smooth variations instead step change in control variable to minimize input power of IM was proposed in [53]. Flux producing current (ids) was considered as variable. Torque producing current (iqs) also adjusted in accordance with ids to avoid deterioration in the torque. From the experience of the authors in [71], a $7.5 \mathrm{hp}$ motor took 7 seconds for completing minimization program (reduces flux step by step until input power is minimized) and the minimization process depends on the motor time constant. Thus longer time for high rated motor and shorter time for larger rated slip. Moreover fast convergence produce more ripples in the torque. The squared rotor flux was adjusted in [75] until the measured input power reached to minimum. The controller depends on rotor resistance and its variations also taken into account. Three indirect vector control schemes namely, stator flux field orientation, rotor flux field orientation and air gap flux field orientation used in [76] for optimizing IM torque and efficiency and concluded that rotor flux field orientation offers best optimal efficiency.

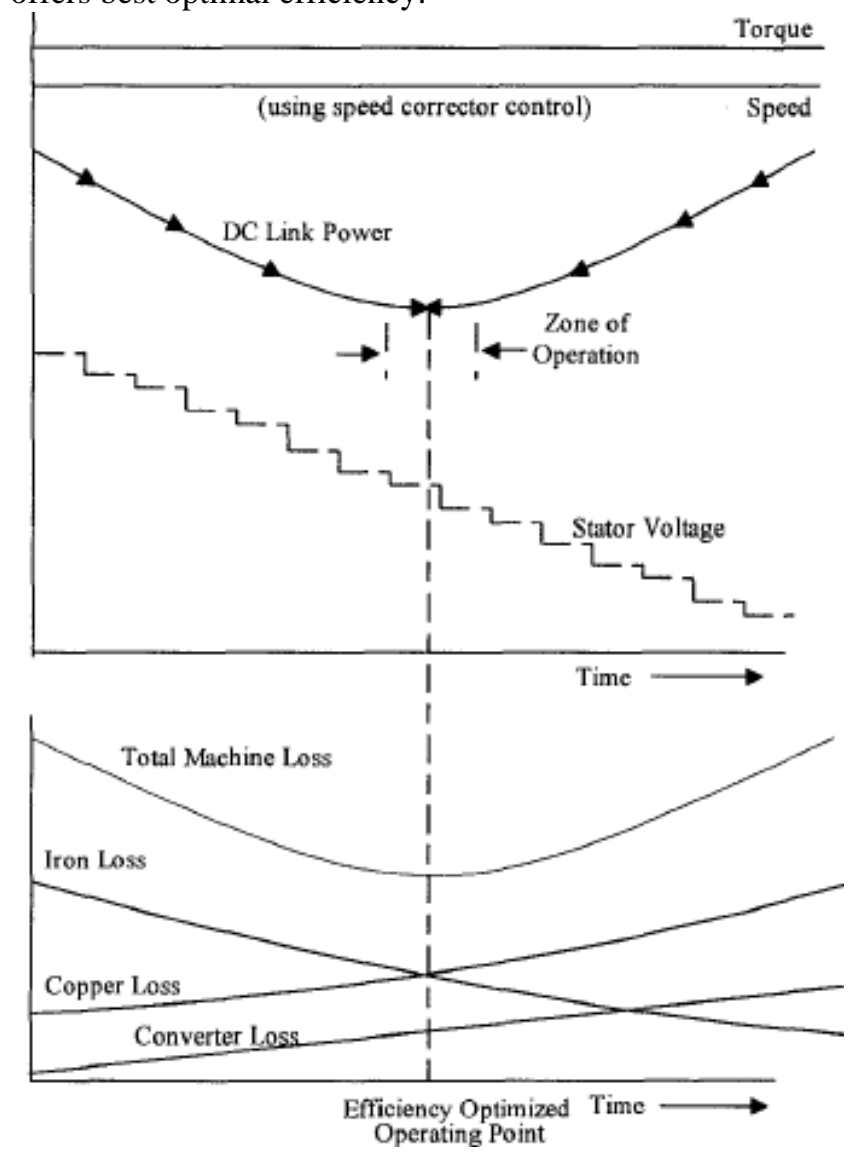

Fig. 10 Perturbation Optimizing Control

\section{(iii) AI and NIA Based Controllers}

Fuzzy logic based search control for optimizing IM efficiency is described in [77]-[80]. Loss minimization during transient state by adjusting flux level using fuzzy logic proposed in [77]. Voltage was considered as a controlling variable in [78]. For both steady state and transient state, fuzzy logic used to optimize motor efficiency in [79]. In Ref [80], fuzzy logic was used to decrement flux up to the drives settled down minimum input power. But the speed or torque command changes, the efficiency optimization using fuzzy abandoned and the rated flux was established to get the best transient performance. Feed forward torque compensator 
used to reduce torque pulsation.

\section{(iv) Both LMC and Search Control}

In Ref [81]-[83], both LMC and SC are used to analyze induction motor efficiency optimization. The developed controller in [81] ensures to retain good features of both the LMC and SC, while eliminating their major drawbacks. Authors used input power in order to identify on-line the loss function parameters and optimize flux value. Therefore slow convergence (drawback of SC) and parameter variation (drawback of LMC) were eliminated. Hybridization of LMC and search control was performed in [82] and achieved good results with rough knowledge of parameters.

LMC compared with SC in [83] and concluded that the LMC is more appropriate in FOC because optimal flux can be imposed in a short time where as search control vary the flux continuously which produce more oscillation in the torque.

\section{(v) Other controls}

A new approach to IM efficiency optimization using natural variables is presented in [84]. Core loss resistance and saturation dependent magnetizing inductance were used as variables to find optimal rotor flux and corresponding minimum losses. The controller was implemented in stationary reference frame through input-output linearization with decoupling technique.

Optimal slip control used to implement maximum torque per ampere control of IM in [85]. The specialty of this technique is that it can be implemented in the same drive which is already having v/f control. Torque command of the torque loop in IM drive is set based on the optimal slip control in [86].

Ref [87] explained how energy saving work can be applied in IM through proper ventilation. Authors compared the properties of a machine with its own and outside ventilations. A $3 \mathrm{hp}$ motor with foreign ventilation, the lowering of temperature is the most significant for a supply voltage frequency near the rated one. In case of own ventilation, low temperature is obtained when the supply frequency is much less than the rated one. Own ventilation helped to decrease the winding temperature.

Ref [88] presented terminal impedance control for energy saving in IM and is good for practical applications because no speed transducer required. Authors suggested that this controller is effective upto $35 \%$ load and can be saved up to $10 \%$ of total energy consumed by the motor.

Intermittent disconnection of the supply is one method to conserve energy which shown in [89]. It is applicable only low hp motor due to transient problems during switching. Authors achieved up to $50 \%$ energy saving in the motor and suggested that the switching off one phase of three phase supply during partial load of motor does not contribute any savings.

Performance optimization of IM during soft starting by eliminating supply frequency torque pulsation and keeping line current constant was presented in [90]. Starting torque pulsation is eliminated by triggering back to back connected thyristers at power points at the first cycle of the supply voltage. This technique is not suitable for the motor those are required more starting torque. References [91]-[95] described soft starting techniques to improve IM efficiency.

\section{CONCLUSION}

Efficiency optimization is very much essential not only to electrical systems, it require all the systems to get beneficial in terms of money and also reduction in global warming. This paper presented a review of the developments in the field of efficiency optimization of three-phase induction motor through optimal control and design techniques. Optimal control covered both the broad approaches namely, loss model control and search control. Optimal design covers the design modifications of materials and construction in order to optimize efficiency of the motor. The use of Artificial Intelligence techniques such as artificial neural network, fuzzy logic, expert systems and nature inspired algorithms; Genetic algorithm and differential evolution, evolutionary programming, evolution strategy, simulated annealing in optimization were also included in this paper. Experimental and simulation examples on efficiency optimization were illustrated.

\section{ACKNOWLEDGMENT}

First author would like to thank Ministry of Human Resources and Development (MHRD), Government of India for giving financial support to his research work.

\section{REFERENCES}

[1] G. J Han, S. S. Shapiro, "Statiscal models in engineering, ” Jhon wiley and sons, 1967.

[2] O. W. Anderson, "Optimum design of electrical machines, " IEEE Trans. Vol. PAS-86, 1967, pp. 707-711.

[3] C. Li, A. Rahman, "Three-phase induction motor design optimization using the modified Hooke-Jeeves method, ” Int. J. Electrical Machines and Power Systems, Vol. 18, 1990, pp. 1-12.

[4] R. Fei, E. F. Fuchs, H. Haung, "Comparison of two optimization techniques as applied to three-phase induction motor design, " IEEE/PES winter meeting, new York, 1989.

[5] K. Schittkowski, "NLPQL: a Fortran subprogram solving constraind nonlinear programming problems, "Annals of Operation Research, Vol. 5, 1985, pp. 485-500.

[6] J. Faiz, M.B.B. Sharifian, "Optimal design of three-phase Induction Motors and their comparison with a typical industrial motor," Computers and Electrical Engineering, vol. 27, 2001, pp. 133-144.

[7] O. Muravlev, et al, "Energetic parameters of induction Motors as the basis of energy saving in a variable speed drive, " Electrical Power Quality and Utilization, Vol. IX, No. 2, 2005.

[8] Christian Koechli, et al, "Design optimization of induction motors for aerospace applications, " IEE Conf. Proc. IAS, 2004, pp. 2501-2505.

[9] W. Jazdzynski, "Multicriterial optimization of squirrel-cage induction motor design, " IEE Proceedings, vol. 136, Part B, no.6, 1989

[10] K. Idir, et al, "A new global optimization approach for induction motor design, " IEEE Canadian Conf. Proc. Electrical and Computer Engineering, 1997, pp. 870-873.

[11] Bhim Singh, B. N. Singh, "Experience in the design optimization of a voltage source inverter fed squirrel cage induction motor", Electric Power Systems Research, Vol. 26, 1993, pp. 155-161.

[12] R. Ramarathnam, B. G. Desai, "Optimization of polyphase induction motor design: a nonlinear programming aproach", IEEE Trans. Power Apparatus and Systems, Vol. PAS-90, No. 2, Mar. / Apr. 1971, pp. 570-578.

[13] D. G. Bharadwaj, k. Venkatesan, R.B. Saxena, Induction motor design optimization using Constrained Rosenbrock Method (Hill Algoritm), Computer and Electrical Engineering, 6, 1979, 41-46.

[14] C. J. Eriction, "Motor Design Features for Adjustable-Frequency Drives, " IEEE Trans. Ind. Appl. Vol. 24, No. 2, 1988.

[15] C. Singh, D.Sarkar, "Practical considerations in the optimization of induction motor design, " IEE Proc-B, Vol. 139, No.4, 1992. 
[16] J. W. Kim, et al., "Optimal stator slot design of inverter-fed induction motor in consideration of harmonic losses, " IEEE Trans. Magnetics Vol. 41, No.5, 2005.

[17] A. Boglietti, et al., "No tooling cost process for induction motors energy efficiency improvements, ”IEEE Trans. Ind. Appl., vol. 41, no. 3, 2005, pp. 808-816.

[18] M. Cunkas, R. Akkaya, "Design optimization of induction motor by genetic algorithm and comparison with existiong motor", Mathmatica and Computational Applications, Vol. 11, No. 3. 2006, pp. 193-203.

[19] S. Padma, R. Bhuvaneswari, S. Subramanian, "Application of soft computing techniques to induction motor design", Computation and Mathematics in Elec. and Electronics Engg., Vol 26, No. 5, 2007, pp. 1324-1345.

[20] Jan Pawel Wieczorek, Ozdemir Gol, Z. Michalewicz, “An evolutionary algorithm for the optimal design of induction motors", IEEE Trans. Magnetics, Vol. 34, No. 6, 1998.

[21] M. K. Kim et al, "Multiobjective optimal design of three-phase induction motor using improved evolution strategy, " IEEE Trans. Magnetics, Vol. 34, No.5, 1998.

[22] R. Bhuvaneswari, S. Subramanian, "Optimization of three-phase induction motor design using simulated annealing algorithm", Electric Power Components and Systems, Vol. 33, 2005, pp. 947-956.

[23] C. Thanga Raj, S. P. Srivastava, P. Agarwal, "Optimal design of poly-phase induction motor using particle swarm optimization, " J. Electrical Engineering, Vol. 1, No. 4, April 2008.

[24] C. Thanga Raj, S. P. Srivastava and P. Agarwal, "Differential evolution based optimal control of induction motor serving to textile industry, "' Int. J. of Computer Science, Vol. 35, No. 2, 2008.

[25] A. Kusko, D. Galler, "Control means for minimization of losses in ac and dc motor drives, " IEEE Trans. Ind. Appl. vol. 1A-19, no. 4, 1983 pp. 561-570.

[26] I. Kioskesidis, N. Margaris, "Loss minimization in scalar controlled induction motor drives with search controller, "IEEE Trans. Power Electronics, Vol. 11, No. 2, 1996, pp. 213-220.

[27] I. Kioskesidis, N. Margaris, "Loss minimization in induction motor adjustable speed drives, " IEEE Trans. Ind. Elect., Vol. 43, No. 1, 1996 pp. 226-231.

[28] D. S. Kirschen, "Optimal efficiency control of induction machines, " Ph.D dissertation, University of Wisconsin, 1985.

[29] S. K. Sul, M. H. Park, "A novel technique for optimal efficiency control of a current-source inverter-fed induction motor, " IEEE Trans. Power. Elect. Vol. 3, no. 2, 1988, pp. 192-199.

[30] J. R. Pottebaum, "Optimal characteristics of a variable frequency centrifugal pump motor drive, ” IEEE Trans. Ind. Appl. Vol. IA-20, no. 1, 1984, pp. 23-31

[31] S. Sen, S. N. Yeh, "Optimal efficiency analysis of induction motors fed by variable-voltage and variable-frequency source, "IEEE. Trans. Energy Conv., vol. 7, no. 3, 1992, pp.537-543.

[32] F. Abrahamsen, et al., "Efficiency-optimized control of medium size induction motor drives, " IEEE Trans. Ind. Appl. vol. 37, no. 4, 2001 pp. 1761-1767.

[33] D. Xu, D. Zhu, Bin Wu, "High performance induction motor drive with optimized excitation current control," in Proc. IEEE Conf. 2001, pp. 1673-1678.

[34] F. Abrahamsen, et al., "On the efficiency optimized control of standard and high efficiency induction motor in CT and HVAC applications," IEEE Trans. Ind. Appl. vol. 34, no. 4, 1998, pp. 822-831.

[35] D. S. kirschen et al., "Minimizing induction motor losses by excitation control in variable frequency drives, "IEEE Trans. Ind. Appl. vol. 1A-20, no. 5, 1984, pp. 1244-1250.

[36] M. H. Park, S. K. Sul, "Microprocessor based optimal efficiency drive of an induction motor, "IEEE Trans. Ind. Elec. vol. IE-31, no. 1, 1984 pp. 69-73.

[37] S. I. Seleme Jr, et al., "Experimental validation of the minimum energy approach for induction motor control, Proc. IEEE Conf. Systems, Man and Cybernatics, vol. 5, 1993, pp. 78-83.

[38] T. W. Jian, N. L. Schmitz, and D. W. Novotny, "Characteristic induction motor slip valuesfor variable voltage part load performance optimization, ” IEEE Trans. Ind. Appl., vol. PAS-102, no. 1, 1984, pp $38-46$.

[39] F. G. G. Buck, P. Gistelinck, and D. Backer, "A simple but reliable loss model for inverter supplied induction motors, " IEEE Trans. Ind. Appl., vol. IA 20, no. 1, 1984, pp. 190-201.

[40] A. Nabae, et al., "An approach to flux control of induction motors operated with variable frequency power supply, " IEEE Trans. Ind. Appl., vol. IA-16, 1980, pp. 342-349.
[41] Y. Geng et al., "A novel control strategy of induction motors for the optimization of both efficiency and torque response, " in Proc. IEEE Conf. Ind. Electron. Society, 2004, pp. 1405-1410.

[42] C. Thanga Raj, "Improving energy efficiency in partial loaded induction motor-using power electronic controllers, ” J. Engineering and Technology, Vol. 1, No. 2, 2006, pp. 13-17.

[43] A. Abbondanti, " Method of flux control in induction motors driven by variable frequency, variable voltage supplies, " Adjustable speed ac drives, IEEE press, B. K. Bose, ed.

[44] Fang Wang, Yuhui Qiu, "A modified particle swarm optimizer with Roulette selection operator," IEEE conference proceedings of NLP-KE, 2005, pp. 765-768.

[45] S. Sujitjorn, K. L. Areerak, "Numerical approach to loss minimization in an induction motor," Applied Energy, Vol. 79, 2004, pp. 87-96.

[46] B. Pryymak, et al., "Neural network flux optimization using a model of losses in induction motor drives, "Mathematics and Computers in Simulation, Vol. 71, 2006, pp. 290-298.

[47] Sundareswaran K, et al, "Artificial neural network based voltage controller for energy efficient induction motor drives, " IEEE Int. Conf., 1998 pp 410-413.

[48] R. H. A. Hamid, A. M. A. Amin, R. S. Ahmed, A. El-Gammal, "New technique for maximum efficiency of induction motors based on PSO, "IEEE conference proceedings, 2006, pp. 2176-2181.

[49] R. H. A. Hamid, A. M. A. Amin, R. S. Ahmed, A. El-Gammal, "Optimal opearation of induction motors using artificial neural network based PSO, " IEEE conference proceedings, 2006, pp. 2408-2413.

[50] O.S. El-Laben, "Particle Swarm Optimized direct torque control of Induction Motor, ” IEEE Conf. Proc. IECON, 2006, pp. 1586-1591.

[51] C.Cao, B. Zhou et al, "Digital implementation of DTC based on PSO for induction Motors," IEEE Conf. Proc. Intelligent Control and Automation, 2006, pp. 6349-6352.

[52] F. F. Bernal, A. G. Cerrada, "Model-based minimization for DC and AC vector-controlled motors including core satuartion, ” IEEE Trans. Ind. Appl. vol. 36, No.3, 2000, pp. 755-763.

[53] S. Vaez-Zadeh, F. Hendi, "A continuous efficiency optimization controller for induction motor drives, " Energy Conversion and Management, Vol. 46, 2005, pp. 701-713.

[54] G.O.Garcia, "An efficient controller for an adjustable speed induction motor drive, " IEEE Trans. Ind. Elect. Vol. 41, No. 5, 1994, pp. 533-539

[55] C. C. De wit, S. I. Seleme, "Robust torque control design for induction motors: the minimum energy approach," Automatica, vol. 33, no. 1, 1997, pp. 63-79.

[56] S. Lim, K. Nam., "Loss minimization control scheme for induction motors, " IEE proc. Electr. Power appli., Vol. 151, No. 4, 2004, pp 385-397.

[57] N. Tsouvalas, et al., "Asynchronous motor drive loss optimization, " Material Processing and Technology, vol. 181, 2007, pp. 301-306

[58] J. H. Chang, B. K. Kim, "Minimum-time and minimum-loss speed control of induction motors under field oriented control, " IEEE Trans. Ind. Electron. vol. 44, no. 6, 1997, pp. 809-815.

[59] S. N. Vulosavic, E. Levi, "A method for transient torque response improvement in optimum efficiency induction motor drives, " IEEE Trans. Energy Conv., vol. 18, no. 4, 2003, pp. 484-493.

[60] D. H. Kim, "GA-PSO besed vector control of indirect three phase induction motor, " Applied Soft Computing, to be published, DOI:10.1016/j.asoc.2006.04.001

[61] Eric Poirer, Mohsen Ghribi and A. Kaddouri, "Loss minimization control of induction motor drives based on genetic algorithm, " IEEE Conf. Proc. Electrical machines and Drives, IEMDC, 2001, pp. 475-478

[62] L.R. Valdenebro, E. Bim, "A Genetic algorithm approach for adaptive field oriented control of induction motor drives, "IEEE Conf. Proc., Electrical machines and drives, IEMD, WA, USA, 1999, pp. 643-645.

[63] E. S. Abdin et al., "Efficiency optimization of a vector controlled induction motor drive using an artificial neural network, " Proc. Of IEEE conf. IECON, 2003, pp. 2543-2548.

[64] M. Perron, H. L. Huy, "Full load range neural network efficiency optimization of an induction motor with vector control using discontinuous PWM, " in Proc. IEEE Symp. Ind. Electron., vol.1, 2006 , pp. 166-170.

[65] J. Li, L. Xu, Z, Zhang, "A new efficiency optimization method on vector control of induction motor," in Proc. IEEE Conf. Electrical Machines and Drives, 2005, pp. 1995-2001.

[66] B. K. Bose, N. R. Patel, K. Rajashekra, "A neuro-fuzzy base on-line efficiency optimization control of a stator flux oriented direct vector controllrd induction motor drive, "IEEE Trans. Ind. Electron., vol. 44, no. , 1997 , pp. $270-273$. 
[67] Kirschen, N. W. Novotny, T. A. Lipo, "optimal efficiency control of an induction motor drive," IEEE Trans. Energy Conv. Vol. EC-2, no.1, 1983, pp. 561-570.

[68] J.C. marino, T.A. Lipo, V. B. Blasco, "Simple efficiency maximize for an adjustable frequency induction motor drive, ”IEEE Trans. Ind. Appl. vol. 27 , no. 5, 1991, pp. 940-946.

[69] D. Galler, "Energy efficient control of ac induction motor driven vehicles," in Proc. IEEE - IAS Annual Meetin, 1980, pp. 301-308.

[70] J. M. D. Murphy, V. B. Honsinger, "Efficiency optimization of inverter-fed induction motor drives," in Proc. IEEE-IAS Annual Meeting, 1982, pp. 544-552.

[71] D. S. Kirschen, et al., "On-line efficiency optimization of a variable frequency induction motor drive, " IEEE Trans. Ind. Appl. Vol. 1A-21, No. 4, 1985, pp. 610-616

[72] P. Famouri, J. J. Cathey, "Loss minimization control of an induction motor drive, ” IEEE Trans. Ind. Appl. vol. 27, No.1, 1991, pp. 32-37

[73] Kioskesidis, N. Margaris, "Loss minimization in scalar controlled induction motor drives with search controller," IEEE Trans. Power Electronics, Vol. 11, No. 2, 1996, pp. 213-220.

[74] J. G. Cleland, "Design of an optimization controller for inverter fed AC induction motors, "Proc. of IEEE Conference, 1995, pp. 16- 21.

[75] G. S. Kim, et al., "Control of induction motors for both high dynamic performance and high power efficiency, " IEEE Trans. Ind. Electron., vol. 39, 1992, pp. 323-333.

[76] O. Ojo, I. Bhat, G. Sugita, "Steady-state optimization of induction motor drives operating in the field weakening region, "Proc. Power electronics Specialist Conf. 1993, vol. 2, pp. 979-985.

[77] J. M. Eguilaz, et al., "Induction motor optimum flux search algorithms with transient state loss minimization using fuzzy logic based supervisor, ” IEEE Conf. Proc. 1997, pp. 1302-1308.

[78] K. Sundareswaran, S. Palani, "Fuzzy logic approach for energy efficient voltage controlled induction motor drive, "IEEE Power Electronics and Drives Conf. Proc. PEDS 1999, pp. 552-554.

[79] G. C. D. Sousa, B. K. Bose, J. G. Cleland, "Fuzzy logic based on-line efficiency optimization control of an indirect vector controlled induction motor drive, ” IEEE Trans. Ind. Elec. Vol. 42, No. 2, 1995 , pp. 192-198.

[80] J. Moreno, et al., "Fuzzy logic based improvements in efficiency optimization of induction motor drives, " Proc. Of IEEE Fuzzy Systems, 1997, pp. 219-224.

[81] S. N. Vulosavic, E. Levi, "Robust DSP-Based efficiency optimization of a variable speed induction motor drive, " IEEE Trans. Ind. Elect., vol. 50, no. 3, 2003, pp. 560-570.

[82] Chandan Chakraborty, Minh C. Ta, Toshiyuki Uchida and Yoichi Hori, "Fast search controllers for efficiency maximization of induction motor drives based on DC link power measurement", in Proc. IEEE conf. PCC-Osaka, 2002, pp. 402-408

[83] S. Ghozzi, K. Jelassi, X. Roboam, "Energy optimization of induction motor drives," in Proc. IEEE Conf. Industrial Technology (ICIT), 2004, pp. 602-610.

[84] Gan Dong, O. Ojo, "Efficiency optimizing control of induction motor using natural variables, ” IEEE Trans. Ind. Elect. Vol. 53, No. 6, 2006, pp.1791-1798.

[85] M. Cacciato, A. consoli, G. Scarcella, G. Seelba, A. Testa, "Efficiency optimization technique via constant optimal slip control of induction motor drives, " Proc. IEEE Power Electronics, Electric Drives, automation, and Motion, 2006, pp. 32-42.

[86] Y. Geng et al., "A novel control strategy of induction motors for the optimization of both efficiency and torque response, " in Proc. IEEE Conf. Ind. Electron. Society, 2004, pp. 1405-1410.

[87] P. Gnacinski, "Energy saving work of frequency controlled induction cage machine, "Energy Conversion and Management, Vol. 48, 2007, pp. 919-926.

[88] F. I. Ahmed, et al., "Terminal-impedance control for energy-saving in induction motors at no and partial loads using microprocessor, "in Proc. IEE Conf. Power Elect. And Variable Speed Drives, 1994, pp. 336-341.

[89] B. B. Palit, "Energy saving operation at induction motors by voltage reduction at no-and low partial load, " in Proc. IEEE Ind. Appl. Annual Meeting, 1989, pp. 147-151.

[90] G. Zenginobuz, et al., "Performance optimization of induction motors during voltage -controlled soft starting, " IEEE Trans. Energy Conv., vol. 19 , no. 2, 2004, pp. 278-288.

[91] J. Nevelsteen, H. Aragon, "Starting of largr motors-methods and economics, ” IEEE Trans. Ind. Appl. vol. 25, 1989, pp. 1012-1018.

[92] F. Blaabjerg, et al., "Can soft-starters help save energy, " IEEE Ind. Appl. Magazine, vol. 3, 1997, pp. 56-66.
[93] J. Bowerfind, S. J. Campbell, "Application of solid-state ac motor starters in the pulp and paper industry, " IEEE Trans. Appl. vol. 1A-22, no. 1,1986 , pp. 109-114

[94] T. M. Rowan, T. A. lipo, "A quantitative analysis of induction motor performance improvement by SCR voltage control, " IEEE Trans. Ind. Appl. vol. 1A-19, no. 4, 1983, pp. 545-553

[95] W. Deleroi, et al., "Analysis and application of three-phase induction motor voltage controller with improved transient performance, " IEEE Trans. Appl. vol. 25, no. 2, 1989, pp. 280-286

Thanga Raj Chelliah received the diploma in Electrical and Electronics Engineering from the Government Polytechnic College, Nagercoil, India in 1996, Bachelor's degree in Electrical and Electronics Engineering from Bharathiar University, Coimbatore, India in 2002 and the Master's degree in Power Electronics and Drives from Anna University, Chennai, India in 2005. $\mathrm{He}$ is currently working towards the $\mathrm{Ph}$. D degree at Indian Institute of Technology Roorkee, India. From 1996 to 2002, he was with Haitima Textiles Limited, Coimbatore, as an Assistant Electrical Engineer. While there, he was involved in energy conservation activities in the electrical equipments.

S. P. Srivastava received the Bachelor's and Master's degrees in Electrical Technology from I.T. Banarus Hindu University, Varanasi, India in 1976, 1979 respectively and the Ph. D degree in Electrical Engineering from the University of Roorkee, India in 1993. Currently he is with Indian Institute of Technology (IIT) Roorkee, India, where he is a Professor in the Department of Electrical Engineering. His research interests include power apparatus and electric drives.

Pramod Agarwal received the Bachelor's, Master's and Ph. D degrees in Electrical Engineering from the University of Roorkee (now, Indian Institute of Technology Roorkee), India in 1983, 1985, and 1995 respectively. Currently he is with Indian Institute of Technology Roorkee, India, where he is a Professor in the Department of Electrical Engineering. His special fields of interests include electrical machines, power electronics, power quality, microprocessors and microprocessor-controlled drives, active power filters, high power factor converters, multilevel inverters, and dSPACE-controlled converters. 